\title{
The Epidermis and Sensory Organs of Dugesia tigrina (Turbellaria: Tricladida)
}

\author{
A Scanning Electron Microscope Study* \\ Lesley R. Smales and Harvey D. Blankespoor \\ Museum of Zoology, University of Michigan, Ann Arbor, Michigan, USA
}

\begin{abstract}
Summary. The epidermis of $D$. tigrina was examined using the scanning electron microscope. Both dorsal and ventral surfaces are extremely irregular in contour, as well as being permeated by large numbers of pores. Cilia are restricted to the ventral surface, the auricles and that part of the dorsum adjacent to the auricles. Club-shaped receptors, as well as cilia, were seen in the auricles. The epidermis anteriad to the eyespots is indistinguishable from that covering the remainder of the dorsal surface. Light rays could not enter the eyespot through this rough epidermal surface without becoming diffracted in an irregular fashion. It was therefore concluded that visual image perception is not a function of the planarian eyespot.
\end{abstract}

Key words: Planarian - Scanning electron microscopy - Epidermis - Sense organs - Ultrastructure.

Ultrastructural studies of the Tricladida (Skaer, 1961, 1965; MacRae, 1967; Best et al., 1968) have shown that the epidermis consists of a single layer of cells with footlike processes that rest on a basement lamina. This epithelium is penetrated by the ducts of many glands. Some differentiation of the surface occurs as cilia are largely restricted to the ventral surface. By means of scanning electron microscopy of the epidermal surface and sensory receptors of Dugesia tigrina this investigation provides a more complete visualisation of the surface architecture.

Send offprint requests to: Dr. Harvey D. Blankespoor, Biology Department, Hope College, Holland, Michigan 49423, USA

* Supported by Rockefeller Grant GA-HS-7424

The authors wish to thank Mr. J. Ford for his assistance with the photography, Dr. D. Wittrock for reading the manuscript 


\section{Materials and Methods}

Specimens of Dugesia tigrina were fixed in hot buffered $4 \%$ formalin, dehydrated, dried in a criticalpoint dryer, mounted on stubs, coated with about $200 \AA$ of gold and examined with a Jeol-JSM-U3 scanning electron microscope.

\section{Results}

Both dorsal and ventral epidermal surfaces are extremely irregular in contour. This irregularity is enhanced by the large number of pores of varying diameters present over all the epidermis (Figs. 1,3). Structures like secretory droplets are seen in many of these pores (Figs. 2, 4). The ventral surface is covered by rows of cilia between which are groups of microvilli. There are also a few larger bristles although these may be aggregations of secretory material (Fig. 2). On the dorsal surface cilia are restricted to the auricles and the surfaces surrounding them. Clumps of microvilli are situated in surface depressions over the whole dorsum. Other depressions contain ovoid bodies which may be freshly secreted rhabdites (Fig. 4). The surface of the plicate protrusible pharynx (Fig. 5) is covered in a dense layer of microvilli (Fig. 6).

The auricles are ovoid indentations situated one on each side of the triangularshaped head (Figs. 7,9). The epidermis of each auricle is richly supplied with cilia, some of which are on rounded elevations (Fig. 8). Between the cilia are pore openings, microvilli and club-shaped receptors (Fig. 10).

Although the eyespots were readily visible in fresh and fixed material because of their dark pigment cups, close examination of many specimens with the SEM failed to reveal any indication of their presence. Apparently the epidermis above the eyespots is not differentiated in any way to improve the quality of the light rays incident on the eyespots. Ciliates, probably Trichodina sp. (Hyman, 1951 a), were present on the dorsal epidermis of many specimens.

\section{Discussion}

The extreme roughness of the epidermal surfaces has not been mentioned in previous descriptions of Dugesia sp. (Kessel and Shih, 1974) or Polycelistenuis (Bowen and Ryder, 1974). Hyman (1951 b) suggested that mucous secretion played

Fig. 1. Ventral surface: irregularly contoured, ciliated surface. Scale $=10 \mu \mathrm{m}$

Fig. 2. Ventral surface: microvilli are present between the groups of cilia on the pitted surface. Note the possible larger bristles (arrow). Scale $=3 \mu \mathrm{m}$

Fig. 3. Dorsal surface: irregularly contoured non-ciliated, pitted surface. Scale $=10 \mu \mathrm{m}$

Fig. 4. Dorsal surface: secretory droplets are present in some of the pores. $M$ microvillus; $R$ rhabdites. Scale $=3 \mu \mathrm{m}$ 

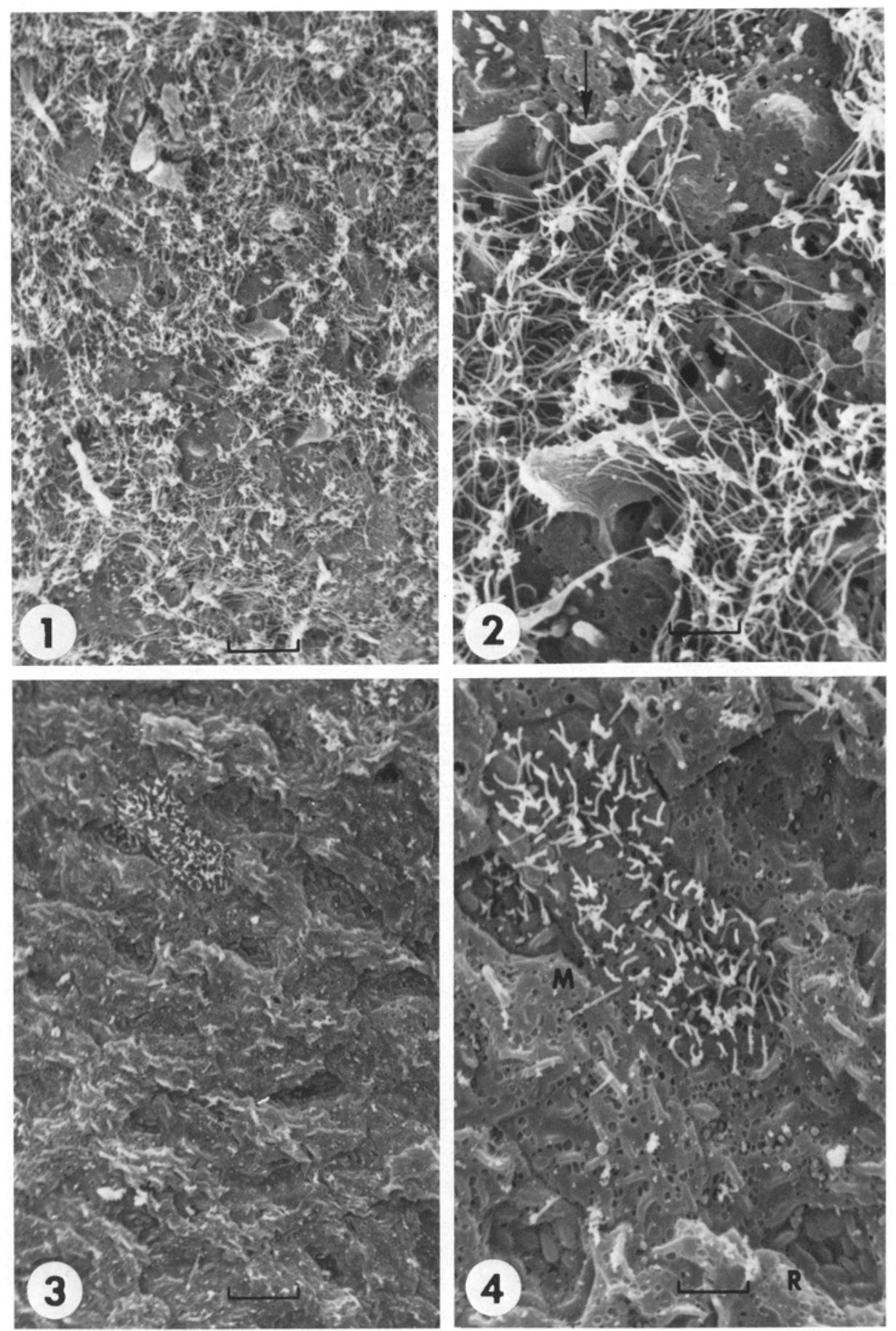

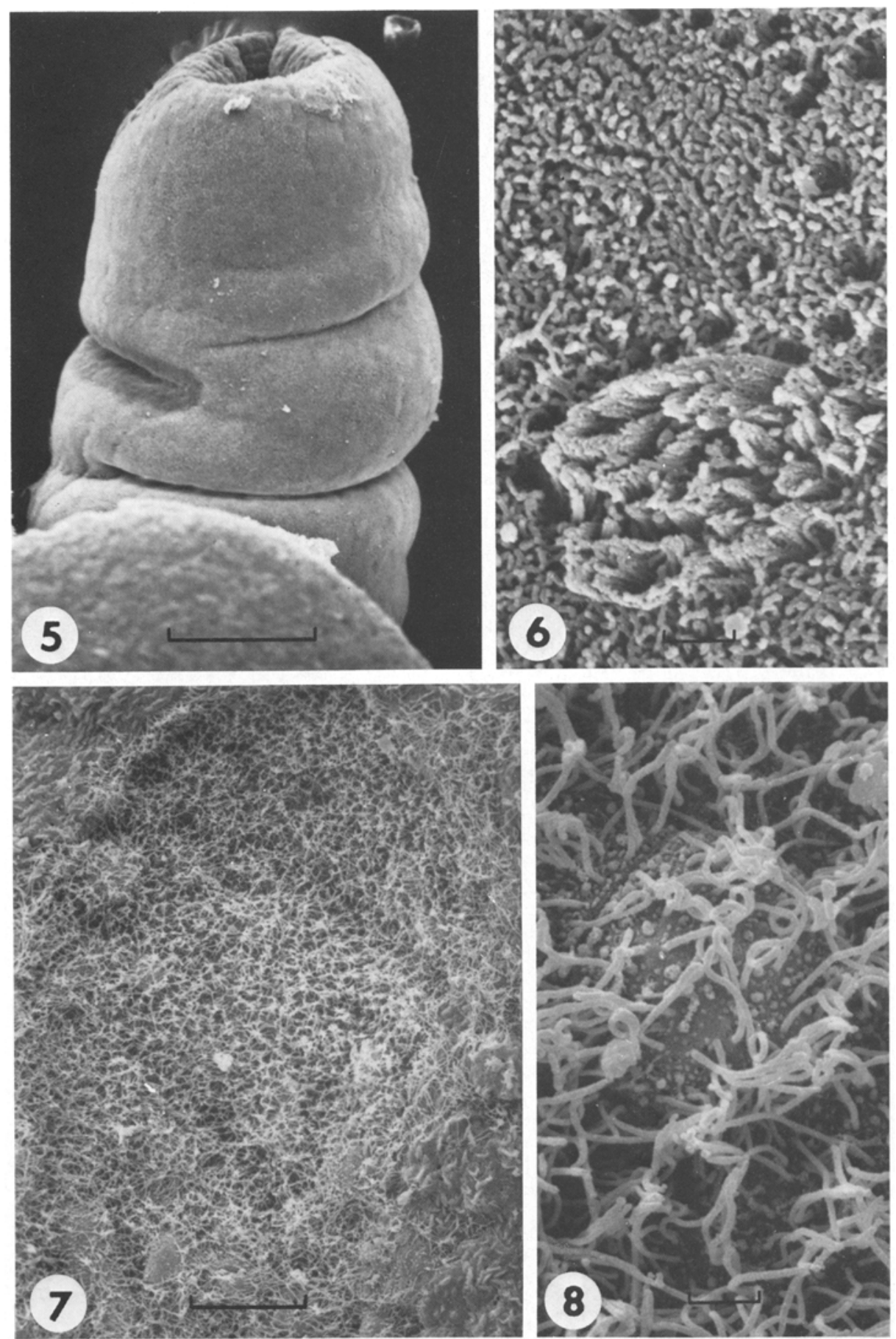

Fig. 5. Everted pharynx. Scale $=100 \mu \mathrm{m}$

Fig. 6. Pharyngeal microvilli. Scale $=2 \mu \mathrm{m}$

Fig. 7. The auricle: cilia extend over the rim of the auricle onto the dorsal surface. Scale $=22 \mu \mathrm{m}$

Fig. 8. Rounded elevation within the auricle with cilia, pore openings and possible secretory droplets. Scale $=1.5 \mathrm{um}$ 

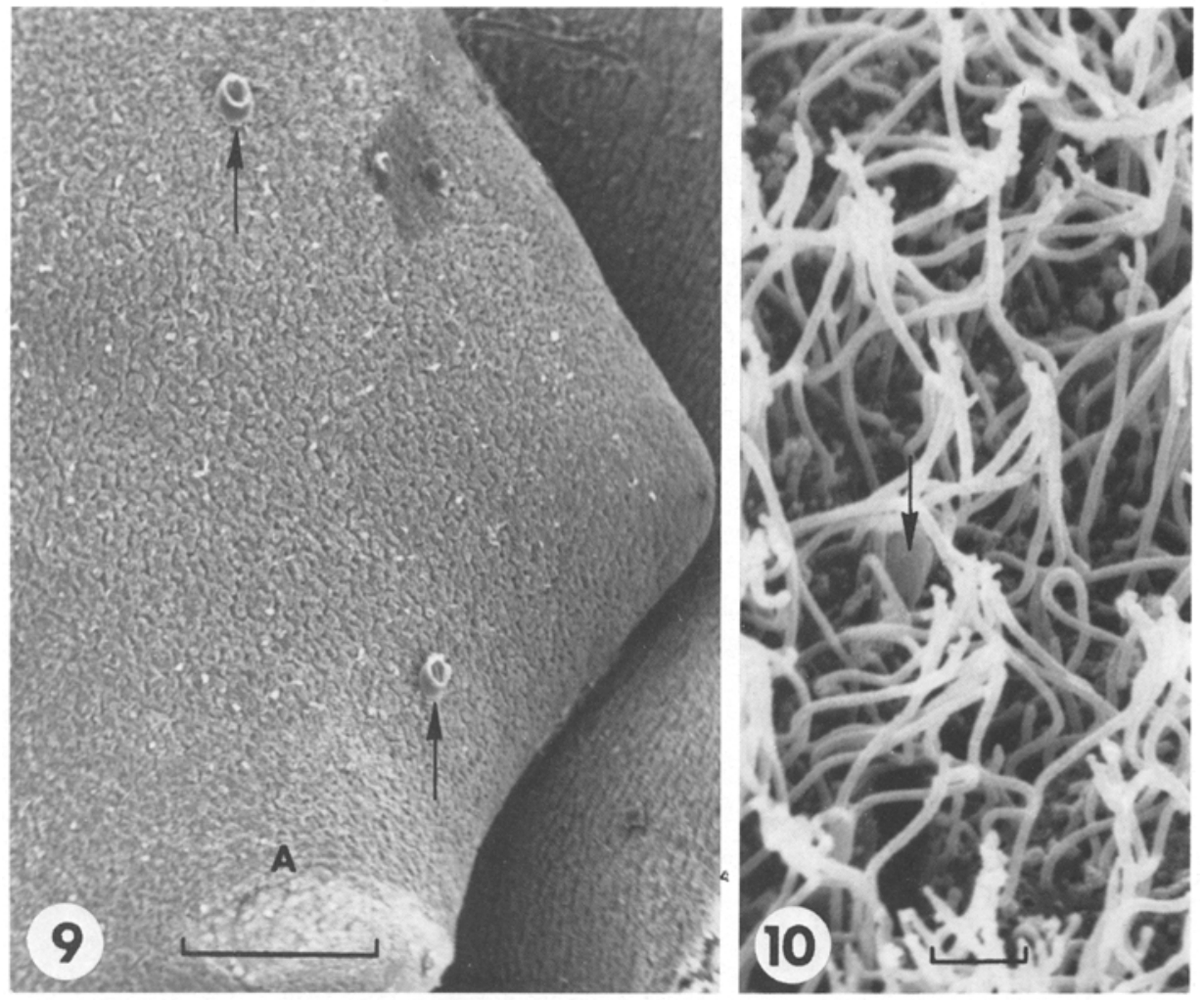

Fig. 9. Anterior dorsal end of D. tigrina with typical triangular-shaped head. There is no surface indication of the eyespots. Note the Trichodina sp. (arrow). A auricle. Scale $=200 \mu \mathrm{m}$

Fig. 10. Auricular cilia: note the club-shaped receptor (arrow). Scale $=1 \mu \mathrm{m}$

an important role in the gliding motion of turbellarians, even the aquatic forms. Such lubrication would be especially important where the epidermis is rough.

The ciliated area associated with the auricles on the dorsal surface is more extensive than previously reported. Probably these cilia are involved with directing currents of water across the auricular region. The pockets of rhabdite-like bodies were seen only on the dorsum. The appearance of these corresponds to the TEM views of rhabditogen cells, discharging rhabdites into the epithelial surface, presented by Bedini and Papi (1974). Therefore, these bodies are probably rhabdites being discharged. The rhabdite-like bodies described by Kessel and Shih (1974) resemble secretory droplets rather than rhabdites. Similarly, the microvilli described by these authors, as well as the thread-like extensions to rhabdites (Bowen and Ryder, 1974) resemble secretory droplets. The fixation procedures used in this study may have given better differentiation of microvilli, rhabdites, mucus and secretory granules. The presence of club-shaped receptors amongst the auricular cilia has been described by MacRae (1967). The cilia found on rounded elevations within the auricles, although structurally similar, might be functionally differentiated from other auricular cilia. 
Ultrastructural studies of the planarian eyespot have been conducted by various investigators on several different planarians, including $D$. tigrina (MacRae, 1964). D. japonica (Kishida, 1967) and D. dotorocephala (Carpenter et al., 1974). Carpenter et al. (1974) found that rhabdites and dense pigment granules were absent from the epidermal surface above the eyespot leaving it optically clear, and suggested that this modification was obviously a functional advantage. The area of optically clear epidermis is about equivalent to that of the auricles and is located near the midline between them. It is unlikely that any surface differentiation of the epidermis above the eyespots would pass unnoticed. However, there is a complete absence of any surface modification such as smoothness or lack of pores.

Light appears to be able to pass freely to the pigment cups of the eyespots and mechanisms to control the amount of light reaching them are present (Carpenter et al., 1974). However, there does not appear to be any surface structure associated with control of light to the eyespots. Light rays passing through the epidermis would be diffracted in a haphazard manner depending on the contours of the surface through which they passed. This would appear to limit the efficiency of the eyespots.

\section{References}

Bedini, C., Papi, F.: Fine structure of the turbellarian epidermis. In: Biology of the turbellaria (N. Riser and M.P. Morse, eds.). New York: McGraw-Hill 1974

Best, J.B., Morita, M., Noel, J.: Fine structure and function of planarian goblet cells. J. Ultrastruct. Res. 24, 385-397 (1968)

Bowen, I.D., Ryder, T.A.: The fine structure of the planarian Polycelis tenuis (Iijima). III. The epidermis and external features. Protoplasma (Wien) 80, 381-392 (1974)

Carpenter, I.S., Morita, M., Best, J.B.: Ultrastructure of the photoreceptor of the planarian Dugesia dotorocephala. 1. Normal eye. Cell Tiss. Res. 148, 143-158 (1974)

Hyman, L.H.: The invertebrates. Vol. I. Protozoa through ctenophora. New York: McGraw-Hill 1951 a

Hyman, L.H.: The invertebrates, Vol. II. Platyhelminths and rhyncocoela. New York: McGraw-Hill $1951 \mathrm{~b}$

Kessel, R.G., Shih, C.Y.: Scanning electron microscopy in biology: a student's atlas on biological organization. New York: Springer 1974

Kishida, Y.: Electron microscope studies on the planarian eye. 1. Fine structure of the normal eye. Sci. Rep. Kanazawa Univ. 12, 75-110 (1967)

MacRae, E.K.: Observations on the fine structure of photoreceptor cells in the planarian Dugesia tigrina. J. Ultrastruct. Res. 10, 334-349 (1964)

MacRae, E.K.: The fine structure of sensory receptor processes in the auricular epithelium of the planarian Dugesia tigrina. Z. Zellforsch. 82, 479-494 (1967)

Skaer, R.J.: Some aspects of the cytology of Polycelis nigra. Quart. J. micr. Sci. 102, 295-317 (1961)

Skaer, R.J.: The origin and continuous replacement of epidermal cells in the planarian Polycelis tenuis (Iijima). J. Embryol. exp. Morph. 13, 129-139 (1965) 